\title{
GERMINAÇÃO DE SEMENTES DE Stryphnodendron Mart. OSMOCONDICIONADAS ${ }^{1}$
}

\author{
CAMILA KISSMANN², SILVANA DE PAULA QUINTÃO SCALON ${ }^{3}$, \\ LEANDRO HENRIQUE DE SOUSA MOTA ${ }^{4}$, MARIA DO CARMO VIEIRA ${ }^{4}$
}

\begin{abstract}
RESUMO - Objetivou-se com esse trabalho avaliar a germinação de sementes de três espécies de Stryphnodendron Mart. (Stryphnodendron adstringens (Mart.) Coville, S. obovatum Benth. e S. polyphyllum Mart.) osmocondicionadas em diferentes agentes osmóticos, nos potenciais de -1.0 MPa e -0.5 MPa. Sementes escarificadas em ácido sulfúrico durante 40 minutos foram condicionadas nos seguintes tratamentos: 1) PEG 6000; 2) PEG $6000+\mathrm{KNO}_{3}$, em partes iguais; 3) $\mathrm{KNO}_{3}$; 4) Água e 5) Testemunha, e incubadas em câmara de germinação (BOD) na temperatura de $20^{\circ} \mathrm{C}\left( \pm 2{ }^{\circ} \mathrm{C}\right)$ durante $0 \mathrm{~h}$ (controle), $6 \mathrm{~h}, 12 \mathrm{~h}$ e 24 horas, com luz contínua. Para cada espécie, o delineamento estatístico foi o inteiramente casualizado em esquema fatorial 5 (tratamentos de osmocondicionamento) x 4 (tempos de condicionamento) com quatro repetições de 20 sementes. Foram avaliados a porcentagem de germinação (\%G), índice de velocidade de germinação (IVG), comprimento médio de raiz (CMR) e de parte aérea (CMPA), e massa fresca (MF) e seca (MS) das plântulas condicionadas a -1,0 MPa e, a \%G e IVG daquelas condicionadas a -0,5 MPa. O osmocondicionamento no potencial de $-1,0 \mathrm{MPa}$ não alterou significativamente o desempenho fisiológico das sementes de $S$. obovatum e $S$. polyphyllum, mas foi prejudicial ao desenvolvimento de $S$. adstringens. O condicionamento das sementes de $S$. adstringens e $S$. polyphyllum em potencial de -0,5 MPa promove maior \%G e IVG.
\end{abstract}

Termos para indexação: barbatimão, Cerrado, polietilenoglicol 6000, pré condicionamento, germinação.

\section{GERMINATION OF PRIMED SEEDS OF Stryphnodendron Mart.}

\begin{abstract}
The objective of this study was to evaluate the germination of seeds of three species of Stryphnodendron Mart. (Stryphnodendron adstringens (Mart.) Coville, S. obovatum Benth. and S. polyphyllum Mart.) under priming in different osmotic agents, in osmotic potentials of -1.0 MPa and -0.5 MPa. Seeds scarified in concentrated sulphuric acid for 40 minutes were conditioned in the following treatments: 1) PEG 6000; 2) PEG $6000+\mathrm{KNO}_{3}$, in equal parts; 3) $\mathrm{KNO}_{3}$; 4) Water and 5) Control. Afterwards, they were incubated in a germination chamber (BOD type) at a temperature of $20^{\circ} \mathrm{C}\left( \pm 2{ }^{\circ} \mathrm{C}\right)$ during $0 \mathrm{~h}$ (control), $6 \mathrm{~h}, 12 \mathrm{~h}$ and 24 hours, under continuous light. For each species, the experiment was carried out in a completely randomized factorial with 5 (priming treatments) $\mathrm{x} 4$ (priming time) factors and four repetitions of 20 seeds. The percentage of germination, germination speed index, length of root and aerial parts, and fresh and dry mass of seedlings obtained from seeds conditioned in -1.0 MPa osmotic potential and the $\% \mathrm{G}$ and IGS of those conditioned at $-0.5 \mathrm{MPa}$, were evaluated. Priming in the potential
\end{abstract}

\footnotetext{
${ }^{1}$ Submetido em 05/05/2009. Aceito para publicação em 14/01/2010.

${ }^{2}$ Bióloga, Doutoranda em Biologia Vegetal. UNESP, Departamento de Botânica. Av. 24-A, 1515, CEP 13506-900, Rio Claro, SP. camilakissmann@, hotmail.com.

${ }^{3}$ Docentes da Universidade Federal da Grande Dourados, Rodovia
}

Dourados Itahum, Km 12, CEP: 79804970, Dourados, MS silvana.scalon@ ufgd.edu.br; vieiracm@terra.com.

${ }^{4}$ Aluno do curso de Agronomia, Bolsista PIBIC/CNPq, Universidade Federal da Grande Dourados/FCA, CEP 79804-970, Dourados-MS. leandromota22@bol.com.br. 
of -1.0 MPa did not significantly influence the physiological performance of Stryphnodendron obovatum and S. polyphyllum seeds but the development of $S$. adstringens seeds was adversely affected. Priming of $S$. adstringens and $S$. polyphyllum seeds in potential of $-0.5 \mathrm{MPa}$ results in higher percentage germination and germination speed index.

Index terms: Stryphnodendron, Savanna, polyethylene glycol 6000, preconditioning, germination.

\section{INTRODUÇÃO}

O osmocondicionamento frequentemente propicia uma maior uniformidade e sincronização da germinação, elevado índice de emergência e desenvolvimento das plântulas, mesmo em solos com baixos teores de umidade, maior taxa de crescimento da parte aérea e maior rapidez no amadurecimento (Marcos Filho, 2005). Porém, o efeito do condicionamento depende de muitos fatores dentre eles o estado de deterioração, tempo e temperatura do tratamento, tamanho das sementes, velocidade de absorção de água (associada ao potencial mátrico e potencial osmótico do meio em que as sementes absorvem água), aplicação de elementos nutritivos, tóxicos ou estimulantes às sementes, grau de hidratação alcançado pelas sementes; secagem após o tratamento, número de ciclos de secagem/umedecimento (Lars, 2000).

O osmocondicionamento é uma técnica de embebição controlada das sementes, que visa obter uma germinação mais rápida e homogênea, mesmo sob estresse, conhecida também como priming. A solução deve apresentar uma concentração suficientemente baixa para permitir a embebição das sementes, permitindo que as fases iniciais preparatórias da germinação possam ser completadas, mas suficientemente alta para prevenir a fase caracterizada por alongamento celular e emergência da radícula (Heydecker et al., 1975).

Agentes osmóticos inorgânicos como o $\mathrm{NaCl}, \mathrm{KNO}_{3}$ e $\mathrm{MgSO}_{4}$, e orgânicos como polietilenoglicol (PEG), manitol e sacarose, são utilizados para aumentar a concentração da solução, diminuindo desta forma, o potencial hídrico da mesma. O PEG com alto peso molecular $(6000,8000$, 20000) é muito utilizado uma vez que produz uma solução caracterizada como inerte, estável e sem efeitos tóxicos (Somers et al., 1983) e, simula a deficiência hídrica sem penetrar no tegumento devido ao tamanho de suas moléculas (Villela et al., 1991).

Segundo Haigh et al. (1986), a combinação de sais contendo nitrato e fosfato, pode ser mais efetiva no condicionamento das sementes que as soluções puras de PEG 6000. Assim, associado ou não ao osmocondicionamento, o $\mathrm{KNO}_{3}$ está envolvido na superação de dormência das sementes, uma vez que atua como receptor de elétrons, ao se reduzir na forma de nitrito no interior das sementes, reoxidando o NADPH e aumentando a disponibilidade do NADP para a redução pelas desidrogenases do ciclo da pentose fosfato (Copeland e Mcdonald, 1995).

Quando o condicionamento das sementes é favorável, ocorre o processo de mobilização de reservas, ativação e síntese de algumas enzimas, e início e aumento da síntese de DNA e RNA, disponibilizando as sementes os precursores utilizados na síntese de macromoléculas. Essas sínteses podem estar relacionadas à remoção de certos agentes inibidores da germinação, como o ácido abscíssico (ABA), ou à produção de fatores promotores, como o ácido giberélico (Jeller e Perez, 2003). O aumento da tensão osmótica pelo PEG e outros agentes osmóticos inibe a síntese de alfa amilase, reduzindo o metabolismo nas células da camada de aleurona (Bewley e Black, 1978).

Diversos trabalhos são citados por Sune et al. (2002) sobre o osmocondicionamento com polietilenoglicol (PEG 6000) que melhorou a velocidade e uniformidade de germinação de sementes de diversas hortícolas. Entretanto, o efeito benéfico do condicionamento osmótico também tem sido relatado para algumas espécies florestais, como Miconia condellana Trian. (quaresminha) (Borges et al., 1994), Cedrela fissilis Vell (cedro-rosa) (Carpi et al., 1996) e Adesmia latifolia (Spreng.) Vog. (babosa) (Sune et al., 2002). Porém, outras espécies, como Pterogyne nitens Tul. (amendoim do campo) não apresentaram incremento da porcentagem nem da velocidade de germinação com o uso do PEG 6000 (Tonin et al., 2005).

O estudo do osmocondicionamento representa, assim, uma linha de pesquisa das mais promissoras. Apesar dos estudos já realizados e, em conseqüência da grande diversidade da flora brasileira, ainda há poucas informações a respeito do condicionamento osmótico das sementes de espécies florestais nativas (Lars, 2000). Nesse contexto, o presente trabalho foi realizado com o objetivo de verificar o comportamento germinativo de sementes de espécies de Stryphnodendron Mart. submetidas ao osmocondicionamento.

\section{MATERIAL E MÉTODOS}

Dois experimentos foram realizados no Laboratório 
de Sementes da Universidade Federal da Grande Dourados (UFGD), no ano de 2008, com sementes de Stryphnodendron adstringens, $S$. obovatum e $S$. polyphyllum procedentes de Chapadão do Sul - MS. A cidade está localizada a uma latitude de $18^{\circ} 79^{\prime} \mathrm{S}$ e a $52^{\circ} 62^{\prime} \mathrm{W}$ (IBGE, 2008).

Experimento 1 - Foi realizado com sementes de $S$. adstringens, $S$. obovatum e $S$. polyphyllum coletadas em 2007 e armazenadas em sacos de papel Kraft em temperatura ambiente até instalação do experimento, em julho de 2008. As sementes foram escarificadas com ácido sulfúrico durante 40 minutos, conforme pré-testes realizados. Em seguida, foram condicionadas nos seguintes tratamentos: 1) PEG 6000 (-1,0 $\mathrm{MPa})$; 2) PEG 6000 (-1,0 MPa) $+\mathrm{KNO}_{3}(-1,0 \mathrm{MPa})$ em partes iguais; 3) $\mathrm{KNO}_{3}(-1,0 \mathrm{MPa})$; 4) Água e 5) Testemunha. O cálculo para a concentração de PEG foi obtido de acordo com a equação de Michel e Kaufmann (1973), descrito por Villela et al. (1991) e a concentração de $\mathrm{KNO}_{3}$ de acordo com a equação de Van't Hoff (Hillel, 1971). Para a mistura de $\mathrm{KNO}_{3}$ e PEG 6000 foi desconsiderada a interação entre os dois produtos. As sementes foram, inicialmente, pesadas e colocadas para a pré-embebição em caixas gerbox forradas com duas folhas de papel filtro umidecidas com $15 \mathrm{~mL}$ das respectivas soluções-teste. Os gerbox foram cobertos com filme plástico, para evitar a evaporação. Em seguida, foram incubados em câmara de germinação (BOD) regulada na temperatura de $20 \pm 2{ }^{\circ} \mathrm{C}$ durante 0 (controle), 6,12 e $24 \mathrm{~h}$, com luz contínua. Decorridos esses períodos, as sementes foram retiradas das câmaras de germinação e permaneceram em condições de ambiente de laboratório até atingirem o peso inicial apresentado antes do condicionamento. A semeadura foi realizada em caixas gerbox sobre duas folhas de papel de filtro umidecidas com água e a incubação em BOD em temperatura $20-30{ }^{\circ} \mathrm{C}$ em regime fotoperiódico de $16 \mathrm{~h}$ de luz. Foram avaliados o porcentual de germinação $(\% \mathrm{G})$, índice de velocidade de germinação (IVG) segundo Maguire, 1962, comprimento médio de raiz (CMR), comprimento médio de parte aérea (CMPA) e massas fresca (MF) e seca (MS) das plântulas.

Experimento 2 - Foi realizado em outubro de 2008 com sementes de $S$. adstringens e $S$. polyphyllum colhidas em setembro de 2008. As sementes foram condicionadas nos seguintes tratamentos: 1) PEG 6000 (-0,5 MPa); 2) PEG $6000(-0,5 \mathrm{MPa})+\mathrm{KNO}_{3}(-0,5 \mathrm{MPa})$ em partes iguais; 3) $\mathrm{KNO}_{3}$ (-0,5 MPa); 4) Água e 5) Testemunha, seguindo-se os mesmos cálculos para o preparo das soluções, temperatura e tempos de incubação das sementes e, a mesma metodologia para semeadura, adotadas para o primeiro experimento. Foram avaliados o porcentual de germinação $(\% \mathrm{G})$, índice de velocidade de germinação (IVG) segundo Maguire, 1962.
Por falta de material, esse experimento não foi realizado com sementes de $S$. obovatum.

Procedimento estatístico - O delineamento estatístico foi o inteiramente casualizado em esquema fatorial 5 (tratamentos de osmocondicionamento) x 4 (tempos de condicionamento) com quatro repetições de 20 sementes. Os valores de germinação, obtidos em porcentagem, foram transformados em arco seno (Snedecor, 1962). Os dados foram submetidos à análise de variância e havendo significância, as médias dos tratamentos foram comparadas pelo teste de Tukey, e as de tempo de condicionamento analisados por regressão, ambos a $5 \%$ de probabilidade.

\section{RESULTADOS E DISCUSSÃO}

\section{Experimento 1}

Não foi observada interação significativa entre os fatores para a maioria das características avaliadas nas três espécies estudadas, apenas para a porcentagem de germinação e massa seca da plântula de $S$. polyphyllum a interação foi observada.

Para as sementes de $S$. adstringens houve redução na porcentagem e velocidade de germinação com o aumento do tempo de condicionamento (Figuras 1A e 1B), sendo os maiores valores para ambas as características observadass nas sementes não condicionadas $(0 \mathrm{~h})$, com germinação próxima a $50 \%$. Sementes de S. obovatum apresentaram aumento linear da porcentagem de germinação das sementes, proporcional ao aumento do tempo de condicionamento, sendo o potencial máximo de germinação observado para sementes embebidas por $24 \mathrm{~h}(20 \%)$ (Figura 1C). O IVG de sementes de S. obovatum e S. polyphyllum (Figuras 1D e 1F) não variou em função das horas de embebição das mesmas, com média de 0,7 e 1,3 dias $^{-1}$.

Para $S$. polyphyllum foi observada interação significativa entre os fatores para a porcentagem de germinação das sementes (Figura 1E), entretanto, não houve um padrão de germinação para essa espécie. Os tratamentos de embebição em PEG e em água não proporcinaram variação na porcentagem de germinação das sementes em função das horas de embebição, com médias de $38 \%$ e $30 \%$, enquanto que o tratamento de embebição em $\mathrm{KNO}_{3}$ causou uma redução linear da porcentagem de germinação com o aumento do tempo de condicionamento. A embebição em solução mista de PEG $+\mathrm{KNO}_{3}$ e em água deionizada (testemunha) ajustaram-se ao modelo cúbico, sendo a maior porcentagem observada para sementes embebidas por 12 horas. No entanto, observaram-se diferentes comportamentos de embebição para os diferentes agentes osmóticos. De acordo com 
Bewley e Black (1994), a entrada de água na semente é influenciada por suas propriedades, bem como pelas condições do ambiente no qual se encontra. O gradiente de potencial hídrico é que estabelece o sentido da entrada de água na semente, mas é a permeabilidade da semente que define a taxa de entrada de água, sendo esta influenciada pela morfologia, estrutura, composição e conteúdo de umidade natural da semente, havendo também influência da temperatura de embebição. Como a embebição nos diferentes agentes foi realizada sob a mesma temperatura, é possível que as diferentes respostas na embebição das sementes de S. polyphyllum estejam relacionadas ao peso molecular dos agentes utilizados. O PEG possui elevado peso molecular e, não penetra no tegumento devido ao tamanho de suas moléculas (Villela et al., 1991), enquanto que o $\mathrm{KNO}_{3}$, devido ao baixo peso molecular pode penetrar nos tecidos das sementes causando fitotoxidez, a qual tende a ser mais severa quanto maior o tempo de exposição das sementes à solução (Bonome et al., 2006).
A

S. adstringens

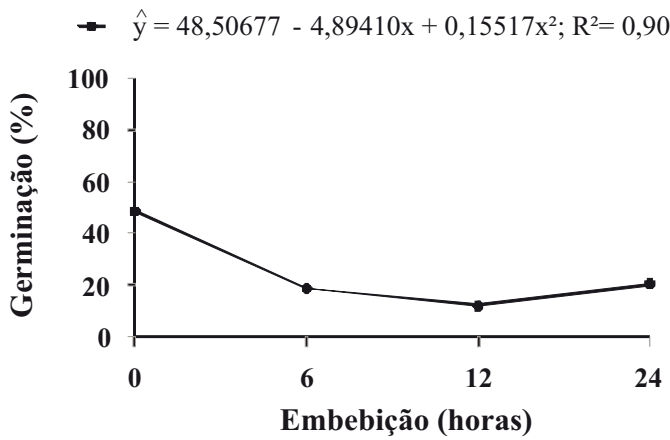

C

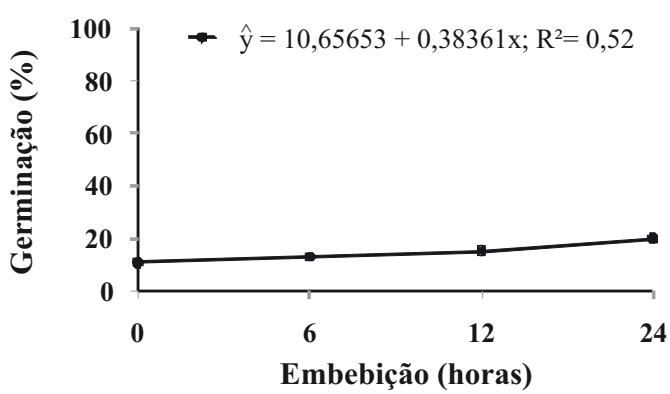

$\mathbf{E}$

-O-PEG $\hat{y}=\bar{y}=38,3$

- - -PEG + KNO3 $\hat{y}=40,00000-7,96324 x+1,09569 x^{2}-0,03344 x^{3} ; R^{2}=1,00$

$\rightarrow$ KNO3 $\hat{y}=43,55647-1,02632 x ; R^{2}=0,90$

—Água $\hat{y}=\bar{y}=30,5$

-Testemunha $\hat{y}=40,00000-10,64745 x+1,31934 x^{2}-0,03729 x^{3} ; R^{2}=1,00$

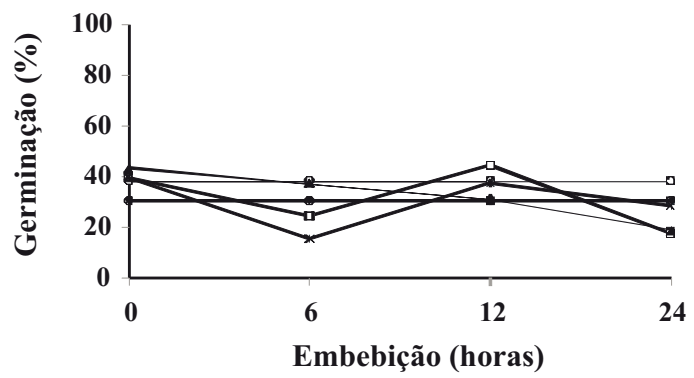

B S. adstringens

- $\hat{y}=1,97637-0,21908 x+0,00695 x^{2} ; R^{2}=0,87$

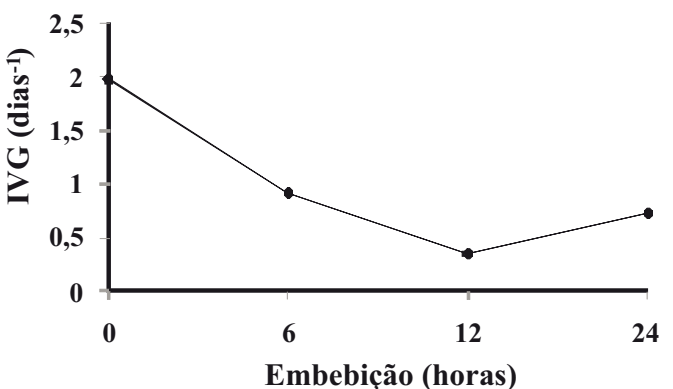

D S. obovatum

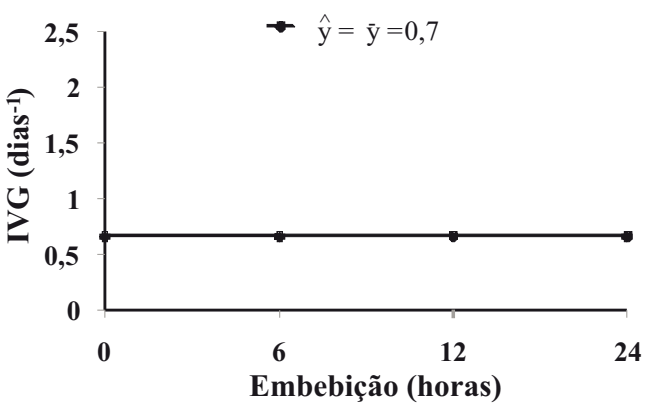

F S.polyphyllum

$\rightarrow \hat{y}=\bar{y}=1,3$

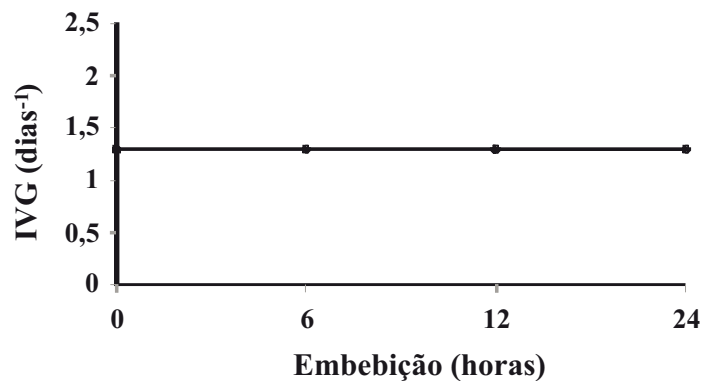

FIGURA 1. Porcentagem de germinação (\%G) e índice de velocidade de germinação (IVG) de Stryphnodendron adstringens Mart. Coville (A, B), S. obovatum Benth. (C, D) e S. polyphyllum Mart. (E, F) submetidas ao osmocondicionamento no potencial de -1,0 MPA. 
Observa-se na literatura que a condição ótima requerida para o osmocondicionamento varia entre espécies, variedades, estoques de sementes da mesma variedade, assim como em relação à condição osmótica que se aplica (Bewley e Black, 1982). Entretanto, o benefício do uso de sais contendo nitrato no controle osmótico de sementes é controverso. Nerson e Govers (1986) afirmam que a utilização desses sais é mais eficiente que a de outros agentes osmóticos, pois, além de não reduzir a disponibilidade de oxigênio na solução, fato constatado quando se utiliza PEG (Heydecker e Coolbear, 1977), estes sais podem servir como potencial fonte de nitrogênio e outros nutrientes essenciais durante a germinação. Entretanto, Frett et al. (1991) observaram efeitos negativos sobre sementes de aspargo quando estas foram condicionadas em solução de $\mathrm{KNO}_{3}$. No presente estudo, o condicionamento em $\mathrm{KNO}_{3}$ também reduziu a germinação de sementes de $S$. polyphyllum.

Para a característica comprimento médio de raiz (CMR) das plântulas de $S$. adstringens e S. polyphyllum (Figuras 2A e 2E), não foi observada variação em função do tempo de condicionamento das sementes (médias de 2,1 $\mathrm{cm}$ e $3,5 \mathrm{~cm}$ ). Entretanto, para essas espécies observou-se redução no comprimento médio de parte aérea (CMPA) com o aumento do tempo de condicionamento (Figuras $2 \mathrm{~B}$ e $2 \mathrm{~F}$ ), com uma pequena elevação dos valores quando as sementes permaneceram condicionadas por 24 horas. Os maiores valores de comprimento de parte aérea foram observados para plântulas originadas de sementes não submetidas ao condicionamento, o que se justifica pelo fato de estas sementes terem apresentado maior velocidade de germinação, uma vez que o condicionamento não tem efeito direto no comprimento das plântulas.

Entretanto, segundo Dell Áquila e Taranto (1986), o osmocondicionamento permite a ocorrência de processos metabólicos adequados ao início da divisão e da expansão celular, induzindo a uma capacidade prolongada de síntese, o que leva a um processo metabólico mais favorável à germinação e ao crescimento das plântulas. Efeitos positivos do condicionamento osmótico no crescimento e acúmulo de matéria verde e matéria seca das plântulas têm sido relatadas para diversas hortícolas, forrageiras e sementes de soja (Sune et al., 2002; Bonome et al., 2006; Del Giúdice, 1996).

Plântulas de $S$. obovatum, originadas de sementes embebidas por 12 horas tiveram maior comprimento de raiz (Figura 2C) enquanto que o comprimento da parte aérea (Figura 2D) teve valor médio de $4,3 \mathrm{~cm}$, não variando com o aumento do tempo de condicionamento. Para esta espécie, os tratamentos de osmocondicionamento não influenciaram no IVG, apenas na porcentagem final de germinação.

Não foi observada variação da massa fresca das plântulas de $S$. adstringens e $S$. obovatum em função do tempo de condicionamento das sementes (médias de 128,0 $\mathrm{mg}$ e 124, $3 \mathrm{mg}$ ) (Figura 3A e 3C). Para a massa seca, não houve variação para $S$. adstringens (média de $25,4 \mathrm{mg}$ ) (Figuras 3B) enquanto que para S. obovatum (Figuras 3D), os maiores valores foram observados para a embebição por 12 horas.

Os valores de massa fresca de S. polyphyllum aumentaram proporcionalmente com o aumento do tempo de condicionamento até 12 horas, reduzindo após esse período (Figura 3E). Para a massa seca (Figura 3F) houve interação entre os fatores estudados. A embebição em PEG e em água proporcionaram um aumento linear da massa seca com o aumento do tempo de condicionamento enquanto que os valores obtidos para a embebição em $\mathrm{KNO}_{3}$ e em água deionizada (testemunha) ajustaram-se ao modelo quadrático, apresentando os maiores valores para a embebição por 12 horas. Os dados obtidos para a embebição em solução mista de $\mathrm{PEG}+\mathrm{KNO}_{3}$ ajustaram-se ao modelo cúbico, porém, os maiores valores também foram observados para o tempo de 12 horas. Os dados obtidos no presente trabalho para $S$. adstringens e $S$. obovatum corroboram àqueles observados por Mendonça et al. (2005) para sementes de Triplaris americana L. (pau-formiga), onde o condicionamento osmótico não influenciou a massa seca das plântulas.

Mendonça et al. (2005) observaram que tanto a embebição em água como em solução de $\mathrm{PEG}+$ ácido giberélico aumentaram a velocidade de germinação de sementes de Triplaris americana L. (pau-formiga) e, recomendam o condicionamento em água para a germinação de sementes dessa espécie, considerando-se os benefícios do custo.

Sune et al. (2002) observaram superioridade nos valores de massa fresca e seca de plântulas de Adesmia latifolia (Spreng.) Vog. (babosa do banhado) submetidas ao tratamento de osmocondicionamento em solução aerada de polietilenoglicol (PEG 6000), concentração de $200 \mathrm{~g} / \mathrm{L}$, por dois dias, em relação aos tratamentos de água quente a $60^{\circ} \mathrm{C}$ por cinco minutos e a testemunha. Segundo os autores, esse resultado pode ser entendido como uma marcante diferença de vigor, entre as plântulas oriundas de sementes de $A$. latifolia osmocondicionadas e aquelas não submetidas a esse tratamento.

Observa-se na literatura que o limite de tolerância das espécies ao PEG é variável e em geral, muito baixo. Rosa et al. (2005) estudaram a germinação de sementes de Ateleia glazioviana Baill (timbó) submetidas a diferentes concentrações de PEG variando de 0 a -1,0 MPa e observaram que a germinação foi inversamente proporcional ao aumento 
da concentração de PEG, sendo nula em -1,0 $\mathrm{MPa}$, sendo este resultado condizente com o esperado, uma vez que a concentração dos sais no meio de germinação, neste caso o PEG, controla a absorção de água pelos tecidos da semente, dificultando ou impedindo o início do processo germinativo. A ausência de germinação em potenciais muito negativos de PEG (-0,9 e - 1,1 $\mathrm{MPa})$ também foi constatada para sementes de Bowdichia virgilioides Kunt (sucupira) (Silva et al., 2001). Para a espécie Adenanthera pavonina L (olhode-dragão), Fonseca e Perez (2003) observaram que o limite máximo de tolerância à solução de $\mathrm{PEG}$ é de -0,4 MPa. Portanto, um segundo experimento foi realizado com as sementes de Stryphnodendron, utilizando-se um potencial osmótico menos negativo, de $-0,5 \mathrm{MPa}$.
A

S. adstringens

$\rightarrow \hat{y}=\bar{y}=2,1$

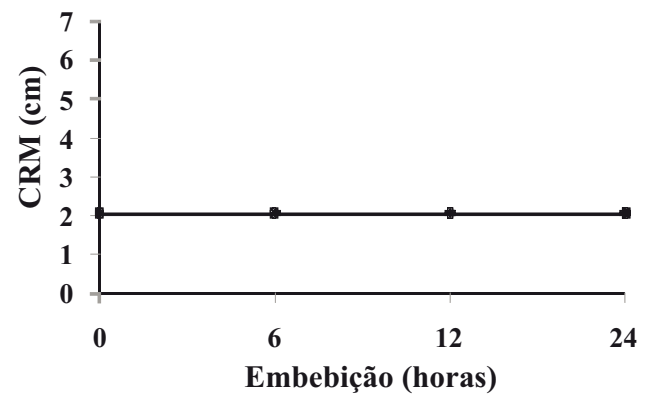

C

S. obovatum

$-\hat{y}=1,44171+0,19182 x-0,00759 x^{2} ; R^{2}=0,51$

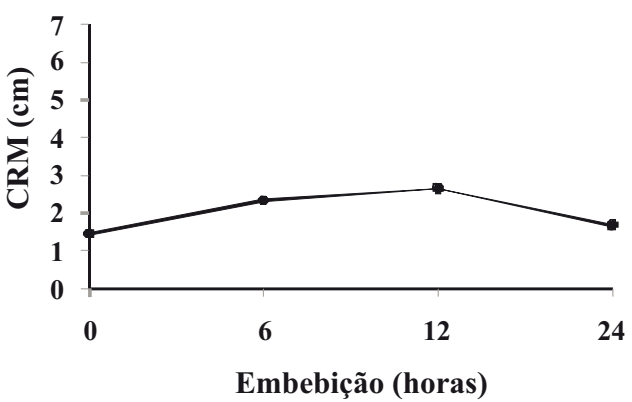

$\mathbf{E}$

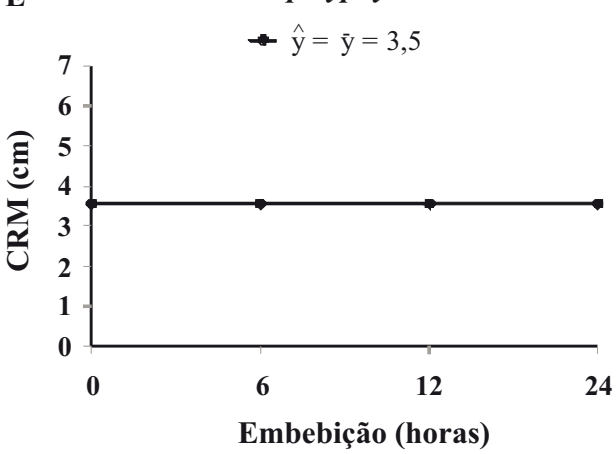

B

S. adstringens

- $\hat{y}=6,53713-0,39642+0,01286 x^{2} ; R^{2}=0,99$

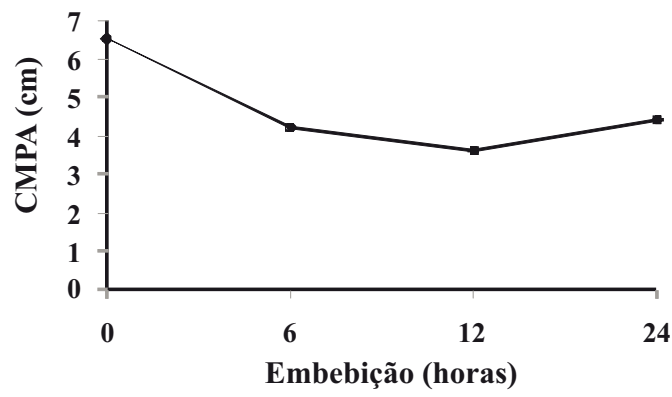

D

S. obovatum

- $\hat{y}=\bar{y}=4,3$

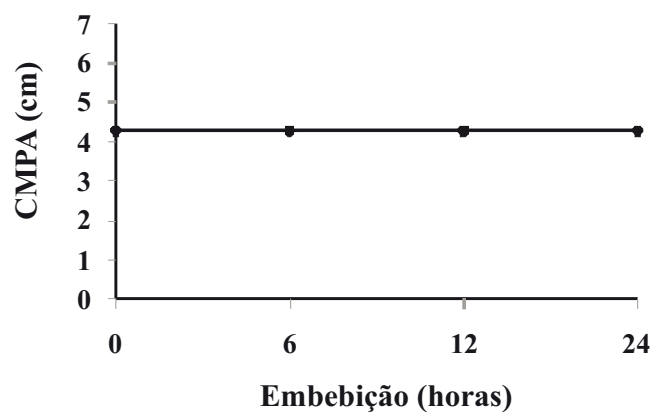

F

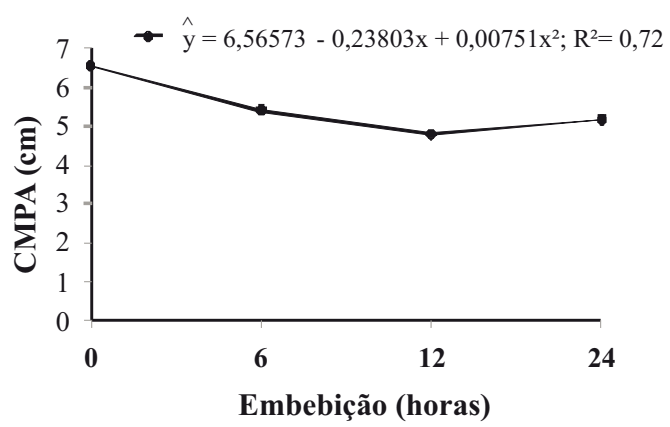

FIGURA 2. Comprimento médio de raiz (CMR) e de parte aérea (CMPA) de Stryphnodendron adstringens (Mart.) Coville (A, B), S. obovatum Benth. (C, D) e S. polyphyllum Mart.(E, F) submetidas ao osmocondicionamento no potencial de -1,0 MPA. 
A

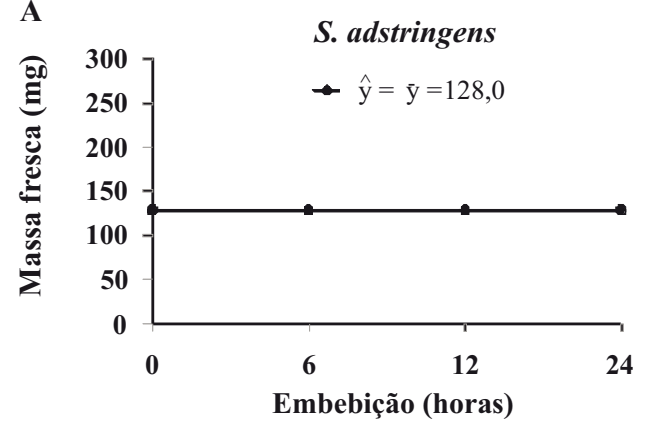

C

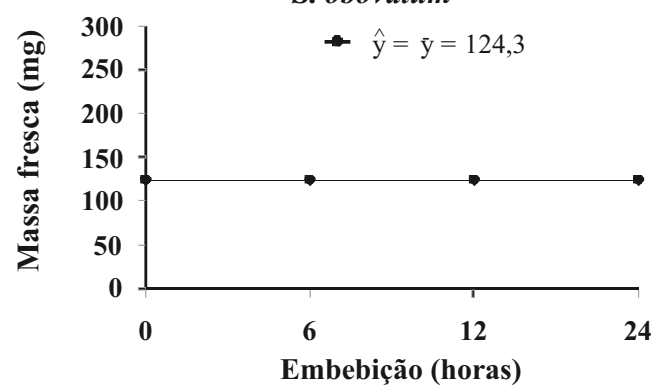

$\mathbf{E}$
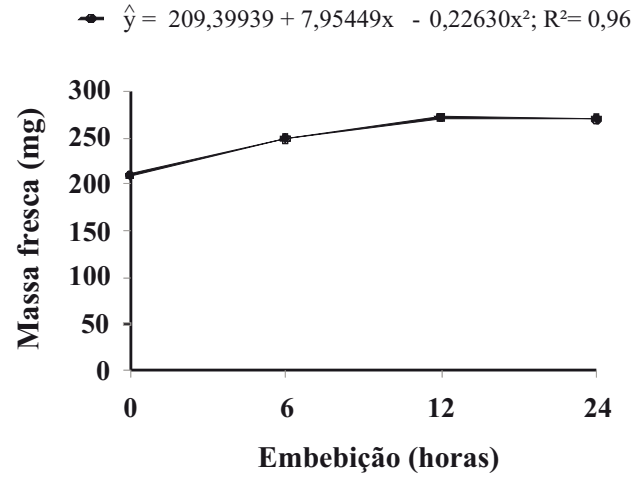

B

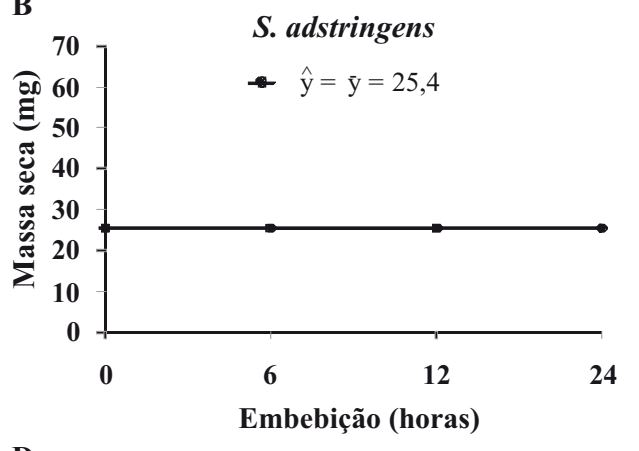

D

S. obovatum

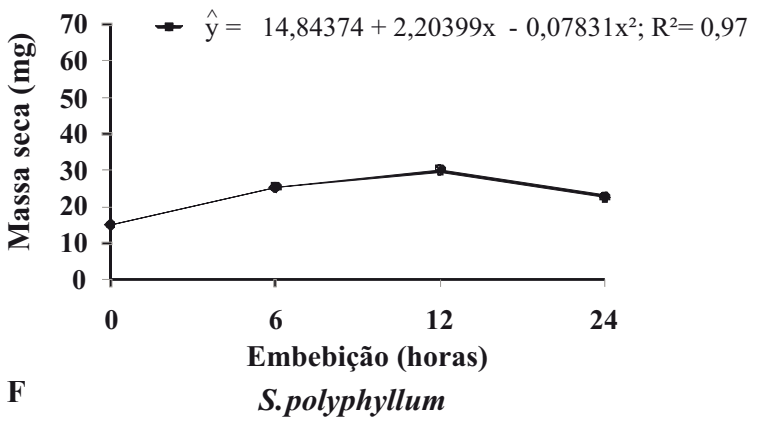

-PEG $\hat{y}=42,00000+0,54762 x ; R^{2}=0,62$

$-\mathrm{PEG}+\mathrm{KNOB} \hat{\mathrm{y}}=40,00000-5,83333 \mathrm{x}+0,89120 \mathrm{x}^{2}-0,02662 \mathrm{x}^{3} ; \mathrm{R}^{2}=1,00$

$+\mathrm{KNO} 3 \hat{\mathrm{y}}=37,88182+2,51540 \mathrm{x}-0,08312 \mathrm{x}^{2} ; \mathrm{R}^{2}=0,76$

- Água $\hat{y}=45,06667+0,53333 x ; R^{2}=0,58$

*Testemunha $\hat{y}=41,54545+2,67677 \times 0,09428 x^{2} ; R^{2}=0,86$

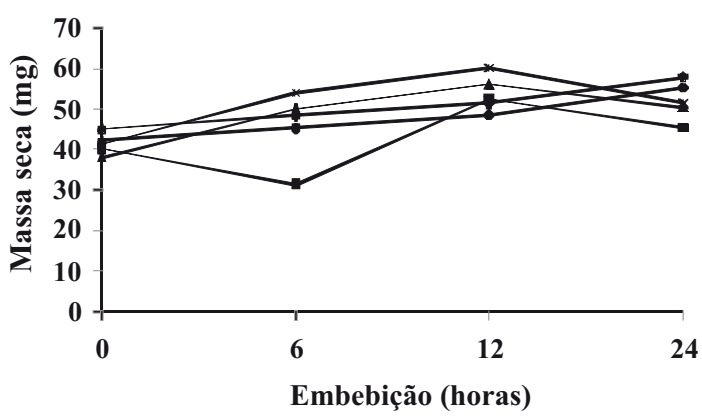

FIGURA 3. Massa fresca e seca de Stryphnodendron adstringens (Mart.) Coville (A, B), S. obovatum Benth. (C, D) e $S$. polyphyllum Mart. (E, F) submetidas ao osmocondicionamento no potencial de -1,0 MPA.

\section{Experimento 2}

Não houve interação entre os fatores tratamentos de osmocondicionamento e tempo de condicionamento para sementes de $S$. adstringens e $S$. polyphyllum condicionadas no potencial de -0,5 MPa. Para ambas as espécies o condicionamento por 12 horas elevou a porcentagem e a velocidade de germinação (Figuras 4A, 4B, 4C e 4D). Sementes osmocondicionadas no presente trabalho apresentaram tendências de melhora de germinação e vigor. Entretanto, outro fator que deve ser levado em consideração no estudo do condicionamento osmótico das sementes é a temperatura de embebição ou incubação adotada.

Segundo alguns autores, as respostas ao osmocondicionamento podem ser mais evidentes quando as sementes são expostas a condições desfavoráveis de temperatura, o que pode ser explicado do ponto de vista da respiração e intercâmbio de $\mathrm{CO}_{2}$, já que as sementes osmocondicionadas apresentam maior atividade metabólica, justificando o melhor desempenho em condições adversas (Duran, 1998). Bradford (1986) e Khan (1992) consideram que o condicionamento osmótico favorece a germinação sob 
condições de estresse. Tonin et al. (2005) observaram que as sementes condicionadas em temperatura mais baixa (10 ${ }^{\circ} \mathrm{C}$ ) apresentaram uma porcentagem de germinação maior que aquelas condicionadas a $27{ }^{\circ} \mathrm{C}$. Para esses autores, o condicionamento a $10{ }^{\circ} \mathrm{C}$ proporcionou um aumento do limite
A

- $\hat{y}=29,97404+6,54240 x-0,21853 x^{2} ; R^{2}=0,79$

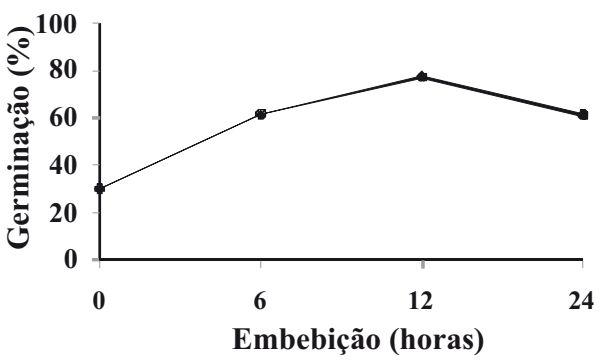

C

S. polyphyllum

- $\hat{y}=63,76366+3,21640 x-0,12149 x^{2} ; R^{2}=0,98$

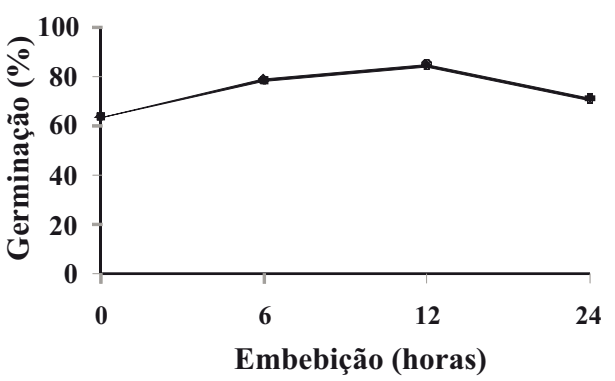

de tolerância a hipóxia. A baixa disponibilidade de oxigênio contribui para a desestruturação do sistema de membranas das sementes e esta desestruturação pode ser revertida pela adequação às variáveis do condicionamento osmótico (Tonin et al., 2005).
B

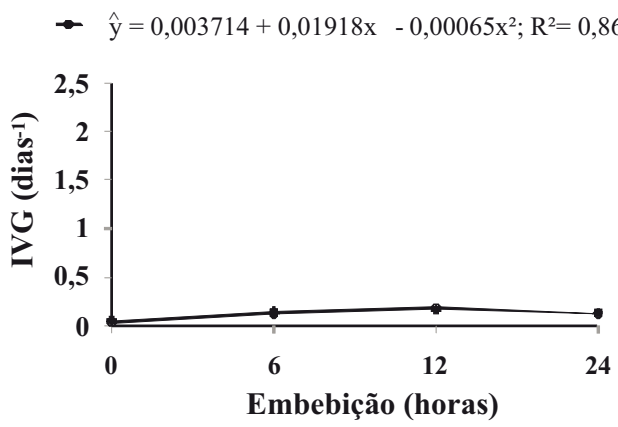

D
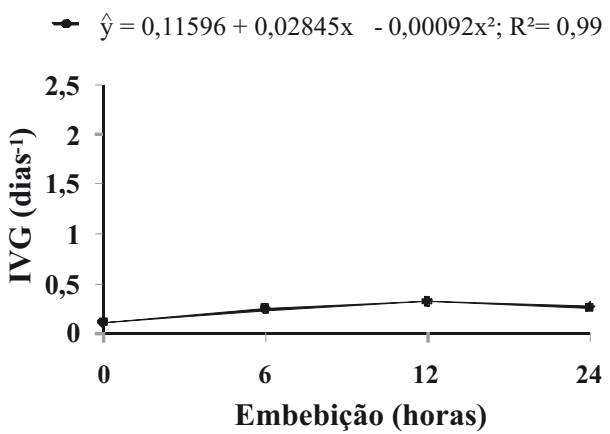

FIGURA 4. Porcentagem de germinação (\%G) e índice de velocidade de germinação (IVG) de Stryphnodendron adstringens Mart. Coville (A, B), S. obovatum Benth. (C, D) submetidas ao osmocondicionamento no potencial de -0,5 MPA.

O condicionamento em PEG 6000 ou em água destilada aumentou a porcentagem de germinação e o vigor das sementes de Cassia excelsa Schrad. (cássia-do-nordeste) em temperaturas subótima e supra-ótima (Jeller e Perez, 2003). Porém, Tonin et al. (2005) não observaram tendência de melhora da viabilidade das sementes de Pterogyne nitens Tul (amendoim do campo), osmocondicionadas em solução mista de $\mathrm{PEG}+\mathrm{KNO}_{3}$ a 10 ${ }^{\circ} \mathrm{C}$ e $27{ }^{\circ} \mathrm{C}$, tanto com o aumento do tempo de exposição do condicionamento, quanto com a germinação nas diferentes temperaturas (sub, ótima ou supra). Sune et al. (2002), observaram incremento significativo na porcentagem de emergência e no índice de velocidade de emergência em sementes de Adesmia latifolia (Spreng.) Vog. (babosa do banhado), condicionadas em solução de PEG 6000 na concentração de $200 \mathrm{~g} / \mathrm{L}$, em relação ao controle, em condições adversas.

Perez e Negreiros (2002) observaram redução do poder germinativo das sementes de Peltophorum dubium (Spreng.) Taub. (canafístula) pré-condicionadas em $\mathrm{KNO}_{3}$ sendo que esta redução foi ainda mais acentuada com o aumento da concentração de $\mathrm{KNO}_{3}$ de $-0,5 \mathrm{MPa}$ para $-1,0$ MPa. De maneira semelhante, sementes de $S$. adstringens e $S$. polyphlyllum condicionadas em $\mathrm{KNO}_{3}$, apresentaram redução do poder germinativo com o aumento da concentração de 0,5 MPa para - 1,0 MPa, com médias $58,83 \%$ e $27,78 \%$ para $S$. adstringens e, $73,44 \%$ e $32,78 \%$ para $S$. polyphyllum, respectivamente. Os autores supracitados sugerem que a presença de íons nitrogênio e potássio, nas soluções de $\mathrm{KNO}_{3}$ 
podem ter ocasionado algum efeito tóxico no embrião ou, ainda, pode ter havido uma limitação na difusão de oxigênio para o interior das sementes (Bradford, 1986).

Segundo a literatura, os solutos usados ou soluções osmóticas com as quais as sementes permanecem em contato devem apresentar algumas características, como por exemplo, não podem ser tóxicos ou causar alterações estruturais; penetrar no sistema de membranas das células; serem metabolizados e nem estarem sujeitos à deterioração microbiana durante o condicionamento das sementes (Bradford, 1986). Entretanto, Santos et al. (2008) ressaltam que os agentes osmóticos comumente utilizados como o $\mathrm{K}_{3} \mathrm{PO}_{4}, \mathrm{KH}_{2} \mathrm{PO}_{4}, \mathrm{MgSO}_{4}$, $\mathrm{NaCl}, \mathrm{KNO}_{3}$, manitol, sorbitol, polietileno glicol (PEG) e glicerol não atendem completamente a essas exigências, sendo importante observar que o critério na escolha é o efeito desejável na semente, não devendo ser tóxico e impedir a etapa final da germinação das sementes.

Segundo Khan et al. (1981), citado por Paixão (1998), o potencial hídrico que normalmente se utiliza no condicionamento osmótico com PEG 6000 está na faixa de $-0,5$ a -2,0 MPa e a duração do tratamento é de 4 a 35 dias. Portanto, é possível que o curto de tempo de embebição das sementes de Stryphnodendron no presente estudo tenha sido insuficiente para promover melhorias na viabilidade das sementes condicionadas.

Considerando-se a influência de diversos fatores externos, tais como a temperatura de embebição, a concentração da solução e a duração do tratamento, e de fatores internos (inerentes da própria semente) no resultado da técnica de condicionamento osmótico (Bradford, 1986), Santos et al. (2008) ressaltam que a melhor combinação dos fatores envolvidos no tratamento e sua otimização devem ser feitas por tentativas para cada lote de sementes. Logo, estudos utilizando outras temperaturas de osmocondicionamento e de incubação, e tempos de embebição devem ser realizados para estas espécies.

\section{CONCLUSÃO}

O osmocondicionamento no potencial de $-0,1 \mathrm{MPa}$ não altera significativamente o desempenho fisiológico das sementes de Stryphnodendron obovatum e S. polyphyllum, mas é prejudicial ao desenvolvimento de $S$. adstringens.

O condicionamento das sementes de $S$. adstringens e $S$. polyphyllum em potencial de -0,5 MPa promove maior porcentagem e velocidade de germinação das sementes.

\section{AGRADECIMENTOS}

À Fundect pelo apoio financeiro e ao CNPq pela concessão de bolsa de mestrado à primeira autora.

\section{REFERÊNCIAS}

BEWLEY, J.D.; BLACK,M. Physiology and biochemistry of seeds in relations to germination. New York: SpringerVerlag, 1978, v.1, 375p.

BEWLEY, J.D.; BLACK, M. Physiology and biochemistry of seeds in relation to germination: development, germination and growth. Berlin: Springer-Verlag, 1982. v.2, 306p.

BEWLEY, J.D.; BLACK,M. Seeds: physiology of development and germination. New York: Plenum Press, 1994. 445 p.

BONOME, L.T. da S.; GUIMARÃES, R.M.; OLIVEIRA, J.A.; ANDRADE, V. de C.; CABRAL, P. de S. Efeito do Condicionamento Osmótico em Sementes de Brachiaria brizantha cv. Marandu. Ciência e Agrotecnologia, v.30, n.3, p.422-428, 2006.

BORGES, E.E.L.; SILVA, L.F.; BORGES, R.C.G. Avaliação do omocondicionamento na germinação de sementes de quaresminha (Miconia condolleana Trian.). Revista Brasileira de Sementes, v.16, n.1, p.90-94, 1994.

BRADFORD, K.J. Manipulation of seed water relations via osmotic priming germination under stress conditions. HortScience, v.21, n.5, p.1105-1112, 1986.

CARPI, S.M.F.; BARBEDO, C.J.; MARCOS FILHO, J. Condicionamento osmótico de sementes de Cedrela fissilis Vell. Revista Brasileira de Sementes, v.18, n.2, p.271-275, 1996.

COPELAND, L.O; MCDONALD, M.B. Principles of seed science and technology. 3.ed. New York: Chapman \& Hall, 1995. 409p.

DEL GIÚDICE, M.P. Condicionamento osmótico de sementes de soja (Glycine max L. Merrill). 1996. 130f. Tese (Doutorado em Fitotecnia) - Viçosa - MG, Universidade Federal de Viçosa - UFV.

DELL ÁQUILA, A.; TARANTO, G. Cell division and DNA synthesis during osmopriming treatment and following germination on aged wheat embryos. Seed Science and Technology, v.14, n.2, p.333-341, 1986.

DURAN, J.M.Acondicionamento e revestimento de sementes. In: SEMINÁRIO PANAMERICANO DE SEMENTES, 15, 1998, Gramado. Resumos. Gramado: CESM/RS; FELAS, 1998. p.107-115.

FONSECA, S.C.L.; PEREZ, S.C.J.G.A. Ação do polietileno glicol na germinação de sementes de Adenanthera pavonina L. e o uso de poliaminas na atenuação do estresse hídrico sob diferentes temperaturas. Revista Brasileira de Sementes, v.25, n.1, p.1-6, 2003. 
FRETT, J.J.; PILL, W.G.; MORNEAU, D.C. A comparison of priming agents for tomato and asparagus seeds. HortScience, v.26, n.9, p.1158-1159, 1991.

HAIGH, A.M.; BARLOW, E.W.R.; MILTHORPE, F.L.; SINCLAIR, P.J. Field emergence of tomato, carrot and onion seeds primed in aerated salt solution. Journal of Amercian Society of Horticultural Sciences, v.111, p.660-665, 1986.

HEYDECKER, W.; HIGGINS, J.; TURNER, I.J. Invigoration of seeds? Seed Science and Technology, v.3, p.881-888, 1975.

HEYDECKER, W.; COOLBEAR, P. Seed treatments for improve performance; survey and attempted prognosis. Seed Science and Technology, v.5, p.353-425, 1977.

HILLEL, D. Soil and Water: physical principles and process. New York: Academic Press, 1971. 288p.

IBGE. Disponível em: <http://www.ibge.gov.br/cidadesat/ topwindow.htm>. Acesso em: 22 de Agosto de 2008.

JELLER, H.; PEREZ, S.C.J. G.de A. Condicionamento osmótico na germinação de sementes de cássia-do-nordeste sob estresse hídrico, térmico e salino. Pesquisa Agropecuária Brasileira, v.38, n.9, p.1025- 1034, 2003.

KHAN, A.A. Preplant physiological seed conditioning. Horticulture Review, v.13, n.25, p.131-181, 1992.

LARS, S. Guide to handling of tropical and subtropical forest seeds. Denmark: Borch Tryc A/S, 2000. 512p.

MAGUIRE, J.D. Speed of germination aid in selection and evaluation for emergence and vigour. Crop Science, v.2, p.176-177, 1962.

MARCOS FILHO, J. Fisiologia de sementes de plantas cultivadas. Piracicaba: Fealq, 2005. 495p.

MENDONÇA, A.V.R.; ARAÚJO, E.C. de; SOUZA, N.A. ; BALBINOT, E. ; SILVA, R.F. ; BARROSO, D. G. Efeito da hidratação e do condicionamento osmótico em sementes de pau-formiga. Revista Brasileira de Sementes, v.27, n.2, p.111-116, 2005.

NERSON, H.; GOVERS, A. Salt priming of muskmelon seeds for low-temperature germination. Scientia Horticulturae, v.28, p.85-91, 1986.
PAIXÃO, G.P.Pré-condicionamento de sementes de quiabo (Abelmoschus escukentus (L.) Moench): efeitos sobre a qualidade fisiológica e potencial de armazenamento. 1998. 56f. Tese de mestrado. Universidade Federal de Viçosa, Viçosa - MG.

PEREZ, S.C.G.A.; NEGREIROS, G.F. Pré-condicionamento na viabilidade e no vigor de sementes de canafístula (Peltophorum dubium (Spreng) Taub) em condições de estresse. Revista Brasileira de Sementes, v.23, n.1, p.175183, 2002.

ROSA, L.S.; FELIPPIA, M.; NOGUEIRA, A.C.; GROSSI, F. Avaliação da germinação sob diferentes potenciais osmóticos e caracterização morfológica da semente e plântula de Ateleia glazioviana Baill (timbó). Cerne, v.11, n.3, p.306314, 2005.

SANTOS, M.C.A; AROUCHA, E.M.M.; SOUZA, M.S. de; SILVA, R.F. da; SOUZA, P.A. de. Condicionamento osmótico de sementes. Caatinga,v.21, n.2, p.1-6, 2008.

SILVA, L.M.M.; AGUIAR, I.B.; RODRIGUES, T.J.D. Seed germination of Bowdichia virgilioides Kunt, under water stress. Revista Brasileira de Engenharia Agrícola e Ambiental, v.5, n.1, p.115-118, 2001.

SNEDECOR, G.W. Statistical methods. Ames, Iowa State University Press, 1962. 422p.

SOMERS, D.A.; ULLRICH, S.E.; RAMSAY, M.F. Sunflower germination under simulated drought stress. Agronomy Journal, v.75, n.2, p.570-572, 1983.

SUNE, A.D.; FRANKE, L.B.; SAMPAIO, T. G. Efeitos do condicionamento osmótico na qualidade fisiológica de sementes de Adesmia latifólia (Spreng.) Vog. Revista Brasileira de Sementes, v.24, n.1, p.18-23, 2002.

TONIN, G.A.; GATTI, A.B.; CARELLI, B.P.; PERES, S.C.J. G.A. Influência da temperaturade condiconamento osmóstico na viabilidade e no vigor de sementes de Pterogyne nitens Tull. Revista Brasileira de Sementes, v.27, p.35-43, 2005.

VILLELA, F.A.; DONI-FILHO, L.; SEQUEIRA, E.L. Tabela de potenciais osmóticos em função da concentração de polietilenoglicol 6000 e da temperatura. Pesquisa Agropecuária Brasileira, v.26, p.1957-1968, 1991. 